\title{
Merdeka Belajar pada Perubahan Bentuk STARS YKPN Yogyakarta di Era Pandemi Covid-19
}

\author{
Yunanta Arief Rusmana \\ Program Studi D3 Gambar Arsitektur, Sekolah Tinggi Arsitektur YKPN Yogyakarta \\ Jl. Gagak Rimang No. 1, Balapan, Yogyakarta \\ Email: yunantaarief@gmail.com
}

\begin{abstract}
Abstrak
Saat ini di segala bidang di dunia telah memasuki era revolusi 4.0, dengan adanya kemajuan IPTEK dan teknologi informasi khususnya, perguruan tinggi diharuskan menyongsong dan mempersiapkan diri menghadapinya. Penyesuaian kurikulum "Merdeka Belajar Kampus Merdeka" saat ini mengakibatkan terjadinya penyesuaian dan review kurikulum, khususnya pendidikan tinggi arsitektur. Di saat yang sama pula saat ini bersamaan dengan adanya pandemi Covid 19 yang melanda di Indonesia dan berpengaruh di semua bidang, termasuk dunia pendidikan, khususnya Sekolah Tinggi Arsitektur (STARS) YKPN Yogyakarta. STARS YKPN yang merupakan perubahan bentuk dari Akademi Teknik (AT) YKPN, dalam menjalankan perannya sebagai institusi pendidikan tidak bisa lepas dari situasi tersebut. Selain hal tersebut, adanya UU Arsitek, dan banyak kebijakan dan peraturan baru dari Kemdikbud, mengharuskan institusi untuk berubah bentuk. AT YKPN yang pada awalnya hanya mempunyai Program studi D3 Gambar Arsitektur, setelah terjadinya perubahan bantuk menjadi STARS YKPN, saat ini mempunyai 2 program studi, yaitu D3 Gambar Arsitektur dan S1 Arsitektur. Dengan adanya perubahan tersebut mengharuskan adanya perubahan kurikulum dan metode pembelajaran, baik pada Program Studi D3 Gambar Arsitektur maupun S1 Arsitektur. Artikel ini bertujuan memberikan gambaran bagaimana berbagai perubahan terjadi, khususnya kurikulum dan motode pembelajarannya.
\end{abstract}

Kata kunci: merdeka belajar, perubahan, bentuk, pandemi.

\section{Abstract \\ Title: Merdeka Belajar on the Changes in the Form of STARS YKPN Yogyakarta in the Covid 19 Pandemic Era}

Currently in all fields in the world have entered the era of revolution 4.0, with the advancement of science and technology and information technology in particular, universities are required to welcome and prepare themselves to face it. The current adjustment of the "Merdeka Belajar Kampus Merdeka" curriculum has resulted reviews for the curriculum, especially for the higher level of education in architecture. At the same time as the Covid 19 pandemic that hit Indonesia and affected all fields, including the world of education, especially the Sekolah Tinggi Arsitektur (STARS) YKPN Yogyakarta. STARS YKPN which is a change in the form of the Akademi Teknik (AT) YKPN, in carrying out its role as an educational institution cannot be separated from this situation. In addition to this, the existence of the Architects Law, and many new policies and regulations from the Ministry of Education and Culture, require institutions to change shape. AT YKPN which initially only had a 3 years Diploma Architectural Drawing Study Program, after the change of form to STARS YKPN, currently has 2 study programs, namely 3 years Diploma Architectural Drawing and Bachelor of Architecture. With these changes, it is necessary to change the curriculum and learning methods, both in the 3 years Diploma Architectural Drawing Study Program and the Bachelor of Architecture Study Program. This article aims to provide an overview of how various changes occur, especially the curriculum and learning methods.

Keywords: independent learning, change, shape, pandemic. 


\section{Pendahuluan}

Memasuki era revolusi 4.0, seiring dengan adanya kemajuan IPTEK, dan teknologi informasi. Perguruan Tinggi harus memiliki kemampuan literasi baru meliputi literasi data, literasi teknologi, dan literasi manusia berakhlak mulia berdasar keyakinan agama. Saat ini perkembangan IPTEK yang berlangsung dengan cepat mengikuti pola logaritma, menyebabkan Standar Pendidikan Tinggi (SN-Dikti) juga mengikuti perubahan yang diikuti adanya Permendikbud No 3 tahun 2020 tentang Merdeka Belajar-Kampus Merdeka (MBKM). Penyesuaian kurikulum MBKM mengakibatkan terjadi penyesuaian dan review kurikulum pendidikan tinggi arsitektur, khususnya Sekolah Tinggi Arsitektur (STARS) YKPN Yogyakarta.

\section{Kebijakan MBKM}

Merujuk pada Permendikbud No. 3 th. 2020 tentang SN-PT, Ps. 18b : Pemenuhan masa dan beban belajar mahasiswa program sarjana atau sarjana terapan dapat dilaksanakan:

1. Mengikuti seluruh proses pembelajaran dalam program studi pada perguruan tinggi sesuai masa dan beban belajar.

2. Mengikuti proses pembelajaran di program studi untuk memenuhi sebagian masa dan beban belajar dan sisanya mengikuti proses pembelajaran di luar program studi.

3. Mahasiswa berkesempatan $\geq 1$ semester (20 sks) untuk menempuh pembelajaran di luar program studi pada PT yang sama; dan $\leq 2$ semester (40 sks) menempuh pembelajaran pada program studi yang sama di PT lain dan/atau program studi lain di PT lain.

4. Tantangan dan kesempatan pengembangan kreativitas, kapasitas, kepribadian, kebutuhan mahasiswa, dan mengembangkan kemandirian.

\section{Metode}

\section{Bentuk dan Pelaksanaan Kegiatan MBKM}

Dari 8 bentuk kegiatan pembelajaran, terdapat 4 bentuk kegiatan yang sudah dilakukan STARS YKPN Yogyakarta, yaitu : magang/Kerja Praktik, membangun desa (Kuliah Kerja Lapangan), studi proyek independen, penelitian/riset.

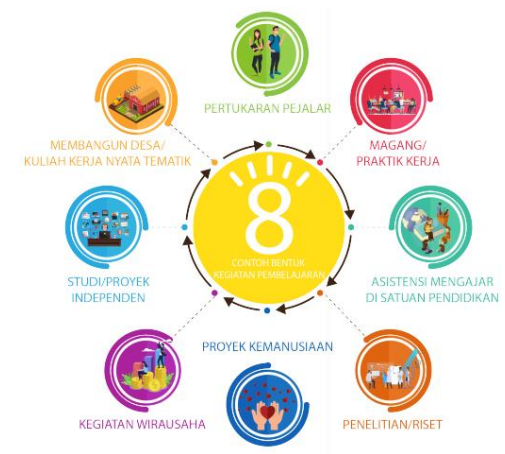

Gambar 1. Bentuk kegiatan pembelajaran sesuai dengan Permendikbud Nomor 3 Tahun 2020 Pasal 15 Ayat 1

Sumber: Direktorat Jenderal Pendidikan Tinggi Kementerian Pendidikan dan Kebudayaan, 2020 
Setiap bentuk kegiatan mahasiswa dibimbing oleh dosen, sehingga sekaligus dibingkai dalam kegiatan Pengajaran, Penelitian dan Pengabdian Masyarakat (Tridharma Perguruan Tinggi). Fasilitas STARS YKPN bagi pelaksanaan MBKM:

1. Menyusun kebijakan/pedoman akademik untuk memfasilitasi kegiatan pembelajaran di luar program studi.

2. Membuat dokumen kerja sama (MoU/SPK) dengan mitra.

3. Program Studi menyusun atau menyesuaikan kurikulum dengan model implementasi kampus merdeka.

4. Memfasilitasi mahasiswa yang akan mengambil pembelajaran lintas program studi dalam Perguruan Tinggi.

5. Menawarkan mata kuliah yang bisa diambil oleh mahasiswa di luar program studi dan luar Perguruan Tinggi beserta persyaratannya.

6. Melakukan ekuivalensi mata kuliah dengan kegiatan pembelajaran luar program studi dan luar Perguruan Tinggi.

7. Jika ada mata kuliah/SKS yang belum terpenuhi dari kegiatan pembelajaran luar program studi dan luar Perguruan Tinggi, disiapkan alternatif mata kuliah daring.

\section{Hasil}

\section{Perubahan Bentuk STARS YKPN Yogyakarta}

Perubahan bentuk dari Akademi Teknik YKPN menjadi Sekolah Tinggi Arsitektur (STARS) YKPN Yogyakarta dilatar belakangi oleh beberapa kondisi.

1. Politik Dalam Negeri

Beragamnya agenda Politik (ada sedikit gejolak), PilPres dan PilLeg berlangsung aman (keamanan stabil), Pemerintahan stabil, pengaruh oposisi tidak begitu signifikan, lahirnya UU Insinyur dan UU Arsitek.

2. Regional

Perang dagang China dan Amerika Serikat sering menimbulkan gejolak ekonomi wilayah, isu konflik Laut China Selatan, agresifitas China dalam segala bidang termasuk penguasaan IT dan AI, perjanjian pasar bebas dan mutual recognition agreement,

3. Global

Pandemi Covid-19 telah melumpuhkan hampir seluruh sendi aktivitas global, proses KBM kuliah praktek dan lain-lain. Berjalan tidak lancar, ekonomi mengalami perlambatan yang cukup signifikan, kemampuan ekonomi masyarakat menurun dan sampai pada isu ketahanan pangan, daya beli, dan minat melanjutkan studi yang terancam

\section{Visi, Misi, Tujuan dan Strategi}

Menjadi perguruan tinggi arsitektur terkemuka, menghasilkan lulusan profesional, berwawasan global, berbasis kearifan lokal yang siap kerja, dan siap berkembang.

Misi STARS YKPN Yogyakarta:

1. Menyelenggarakan pendidikan akademik dan vokasi bidang arsitektur untuk menghasilkan lulusan yang memiliki budi pekerti luhur, 
kemandirian,kewenangan, integritas dan kompetensi yang siap kerja dan siap berkembang.

2. Mengembangkan arsitektur berwawasan global yang peduli kondisi alam, sosial, dan budaya lokal melalui kegiatan pendidikan, penelitian, dan pengabdian kepada masyarakat.

Tujuan STARS YKPN Yogyakarta :

1. Menghasilkan lulusan S1 dan D III bidang arsitektur, yang berbudi pekerti luhur, memiliki kemandirian, kewenangan, integritas,dan kompetensi yang siap kerja dan siap berkembang.

2. Mewujudkan pendidikan di bidang arsitektur berwawasan global yang mempedulikan kondisi alam, sosial, dan budaya lokal yang berkualitas.

3. Mewujudkan kegiatan penelitian dan pengabdian kepada masyarakat di bidang arsitektur berwawasan global yang mempedulikan kondisi alam, sosial, dan budaya lokal dengan melibatkan mahasiswa.

4. Mewujudkan pengelolaan institusi berdasar prinsip good governance (kredibel, transparan, akuntabel, bertanggung jawab, dan berkeadilan).

Strategi terdiri dari 3 tahapan, yaitu:

\begin{tabular}{|c|c|c|}
\hline $2020-2024$ & $2025-2029$ & $2030-2034$ \\
\hline $\begin{aligned} \text { - } & \text { INTERNALISASIV,M,T } \\
\text { - } & \text { RINTIS, JALIN } \\
& \text { KERJASAMA } \\
\text { - } & \text { PELATIHAN } \\
& \text { PENGELOLAAN } \\
& \text { AKADEMIK, NON } \\
& \text { AKADEMIK } \\
\text { - } & \text { PENJAMINAN MUTU } \\
& \text { BID AKADEMIK } \\
\text { - } & \text { PELATIHAN, STUDI } \\
& \text { LANJUTSSDM } \\
\text { - } & \text { PELATIHAN } \\
& \text { PENELITIAN \& PKM }\end{aligned}$ & $\begin{array}{l}\text { - JALIN\& REALISASI, } \\
\text { KERJASAMA } \\
\text { - } \text { PENJAMINANMUTU } \\
\text { SEMUA BIDANG } \\
\text { - } \text { KUALITASTENAGA } \\
\text { KEPENDIDIKAN } \\
\text { - } \text { STUDI LANJUT, JAFUNG } \\
\text { TENAGAPENDIDIK } \\
\text { - } \text { KUALITASDAN } \\
\text { KUANTITASPENELITIAN } \\
\text { DANPKM }\end{array}$ & $\begin{array}{l}\text { - } \text { REALISASI } \\
\text { KERJASAMA } \\
\text { INTERNASIONAL } \\
\text { - STANDARTENAGA } \\
\text { KEPENDIDIKAN MIN. } \\
\text { S1 } \\
\text { - TENAGAPENDIDIK } \\
\text { 50\%S3 } \\
\text { - TERCAPAI KUALITAS } \\
\text { DANKUANTITAS } \\
\text { PENELITIAN DAN } \\
\text { PKM }\end{array}$ \\
\hline
\end{tabular}

Gambar 2. Strategi STARS YKPN Yogyakarta (2020-2034)

Sumber: Renstra STARS YKPN Yogyakarta, 2019

\section{Pembahasan}

\section{Kurikulum S1}

Capaian Pembelajaran (CP) Semester:

1. Semester 1: Teknik Presentasi Manual

2. Semester 2: Teknik Presentasi Digital

3. Semester 3: Bangunan Sederhana/ Rumah

4. Semester 4: Bangunan Umum/ Analisis Tapak

5. Semester 5: Bangunan Umum/ Analisis Kawasan

6. Semester 6: Bangunan Umum (Tematik)

7. Semester 7: Studi Kasus

8. Semester 8: Studi Kasus (Tematik)

Setelah semester 5, mahasiswa bisa bekerja dan membantu kegiatan Penelitian dan Pengabdian pada Masyarakat. 


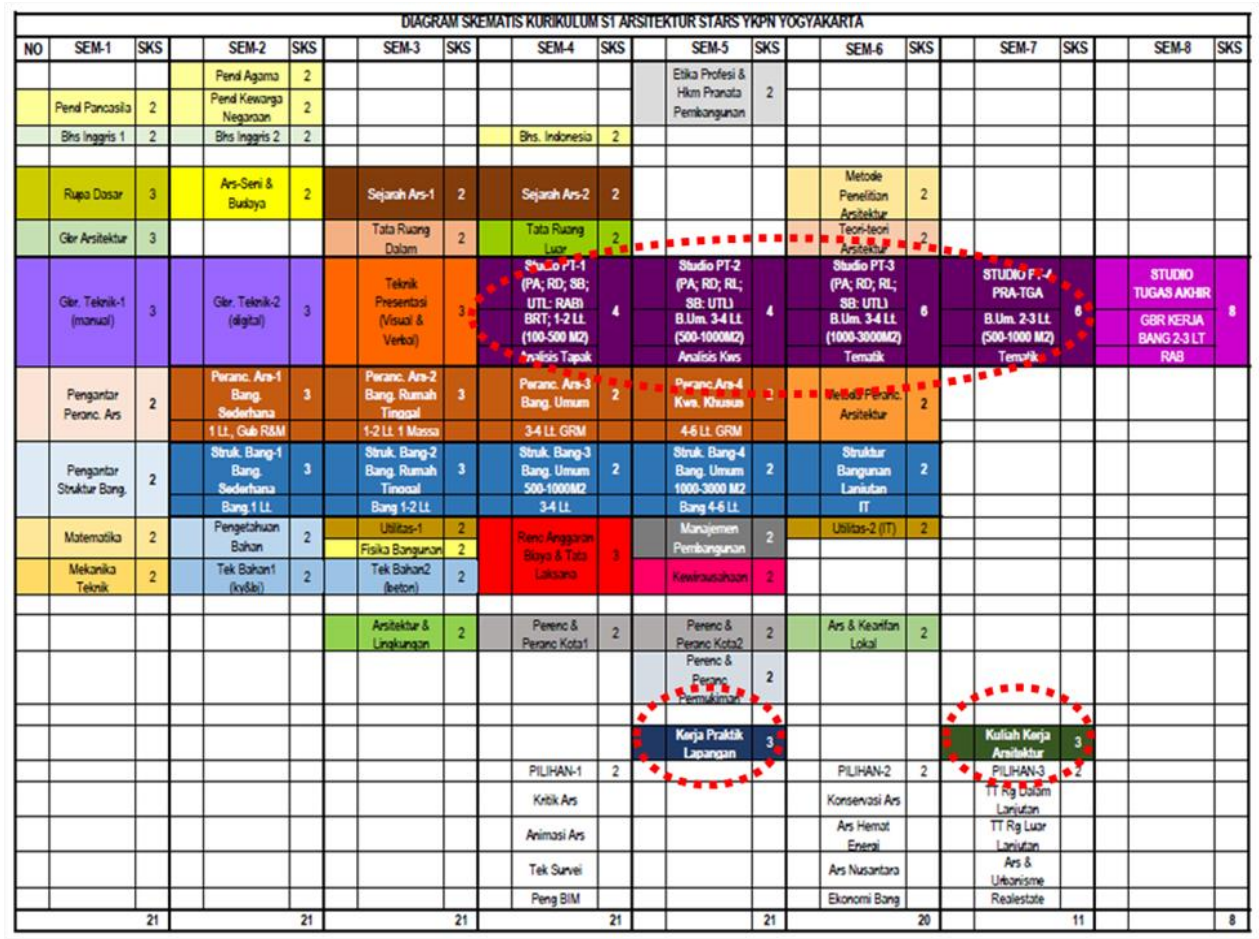

Gambar 3. Kurikulum S1- STARS YKPN Yogyakarta (2019-2024)

Sumber: Dokumentasi Kurikulum, 2019

\section{Kurikulum DIII}

Capaian Pembelajaran (CP) Semester:

1. Semester 1: Teknik Presentasi Manual

2. Semester 2: Teknik Presentasi Digital

3. Semester 3: Bangunan Sederhana/Rumah

4. Semester 4: Bangunan Umum/Analisis Tapak

5. Semester 5: Bangunan Umum/Analisis Kawasan

6. Semester 6: Bangunan Umum/Tematik

Setelah semester 3, mahasiswa bisa bekerja dan membantu kegiatan Penelitian dan Pengabdian pada Masyarakat. 


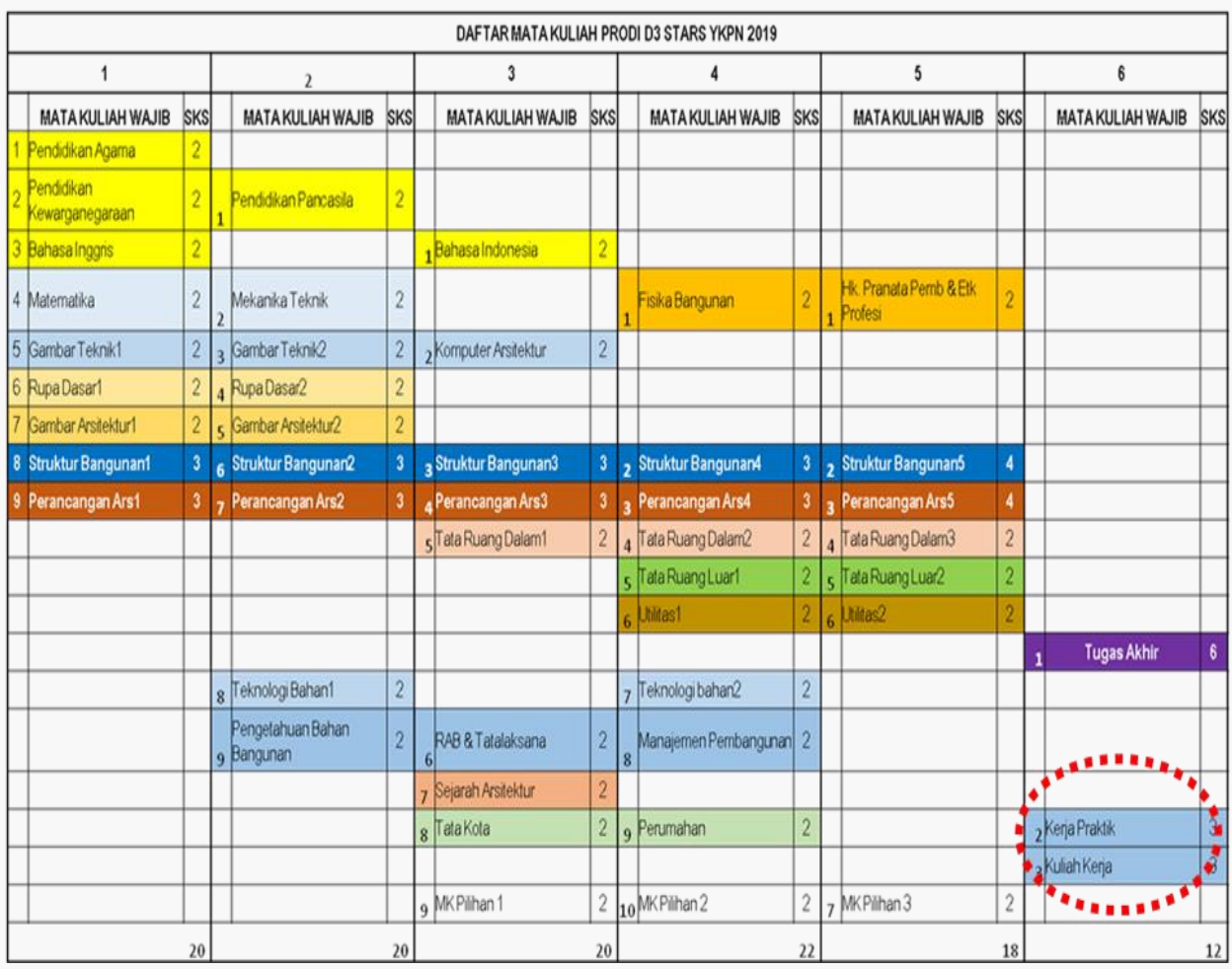

Gambar 4. Kurikulum DIII- STARS YKPN Yogyakarta (2019-2024)

Sumber: Dokumentasi Kurikulum, 2019

\section{Metode Pembelajaran (Hybrid)}

Metode pembelajaran daring (Aplikasi SIATO dan media lain) serta luring manakala diperlukan.

1. Tugas individu

2. Tugas kelompok

3. Simulasi

4. Observasi

5. Inisiasi

6. Pemecahan masalah

7. Diskusi/ webinar

8. Studi preseden/Studi kasus

9. Kerja praktik studio/kerja praktik lapangan

10. Tugas Akhir/Penelitian

Metode luring dengan mengikuti Protokol Covid-19.

\section{Evaluasi Pembelajaran dan Kurikulum}

1. Evaluasi pelaksanaan kurikulum dan kegiatan pembelajaran dilaksanakan tiap akhir semester

2. Evaluasi kecil tiap 2 tahun, evaluasi besar tiap 4 tahun

3. Evaluasi melibatkan: dosen; alumni; pengguna lulusan; Asosiasi Pendidikan Tinggi Arsitektur Indonesia; Ikatan Arsitek Indonesia

\section{Penelitian}

Kegiatan Penelitian dan Pengadian kepada masyarakat bekerja sama dengan masyarakat dan institusi pemerintah dibingkai dengan MoU kerja sama dengan 
Forum BKM Kota Yogyakarta (Forkom_program KOTAKU_KemenPUPR) dengan STARS YKPN Yogyakarta. Saat ini P3M telah memiliki Rencana roadmap kegiatan penelitian, yang merupakan salah satu komponen Tridharma Perguruan Tinggi. Kegiatan penelitian ini juga dimanfaatkan bagi mahasiswa sebagai kegiatan Kuliah Kerja Lapangan (KKL)/Kerja Praktek (KP).

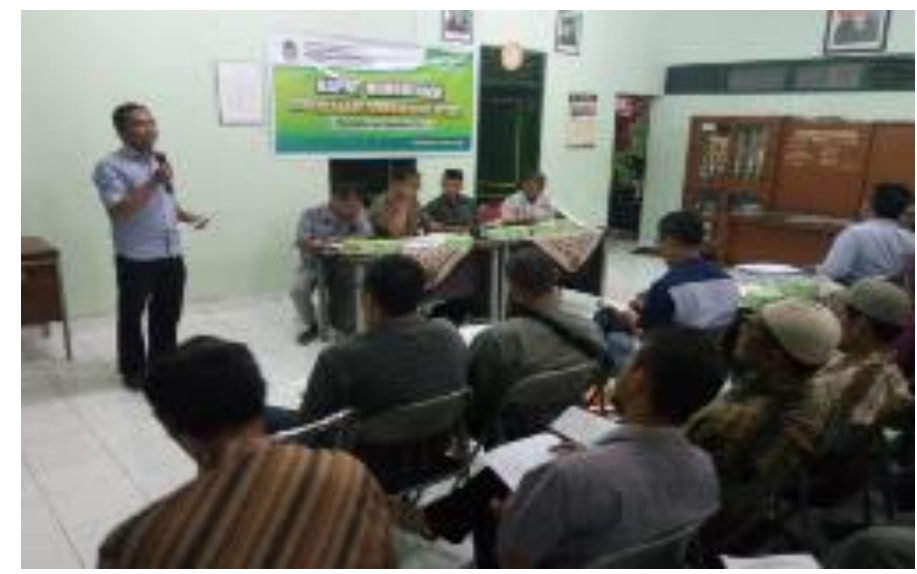

Gambar 5. Kegiatan penelitian STARS YKPN Yogyakarta dengan Kel. Notoprajan Sumber: Dokumentasi peneliti, 2019

Keluaran roadmap penelitian adalah arsitektur berkelanjutan, yang dibagi atas: bangunan (heritage, umum, hunian) dan lingkungan (heritage, kota, desa). Masing-masing bagian mengakomodasi mata kuliah yang terkait.

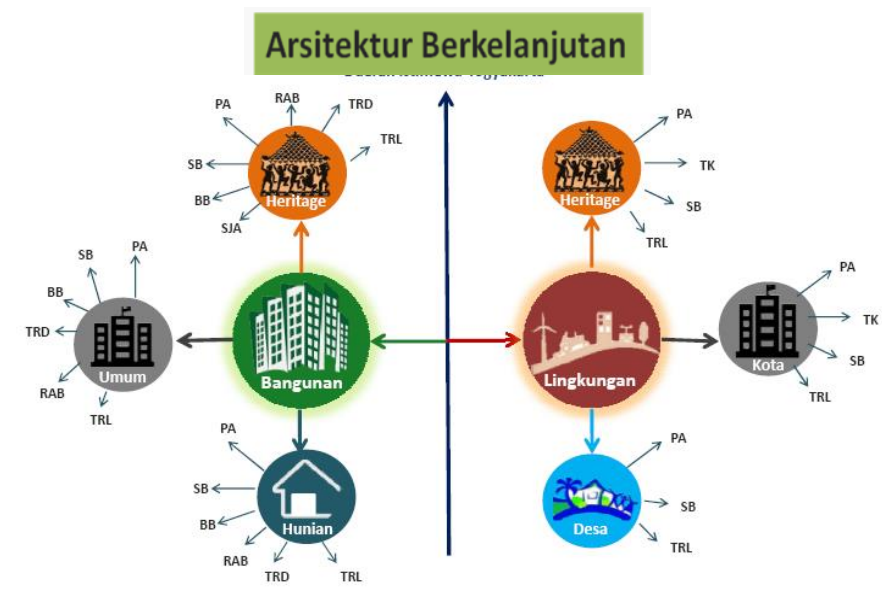

Gambar 6. Road Map P3M STARS YKPN Yogyakarta (2019-2024)

Sumber: Dokumentasi Yunanta, 2020

\section{Pengabdian Masyarakat}

Sebagai implementasi MBKM, salah satu contoh pengabdian kepada masyarakat yang sudah berjalan di STARS YKPN Yogyakarta adalah di Kelurahan Notoprajan dan Kelurahan Giwangan. Kegiatan ini juga dimanfaatkan untuk KKL/KP mahasiswa. 


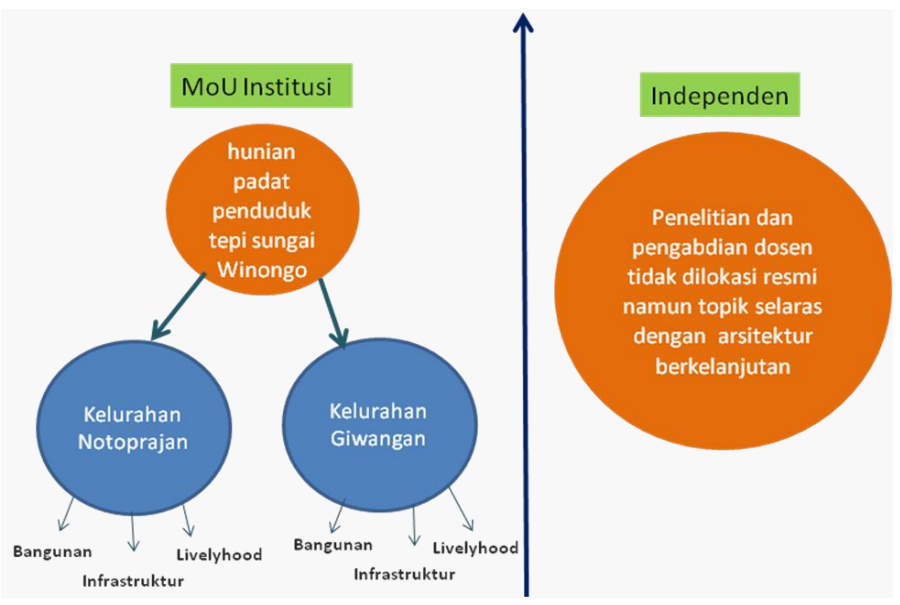

Gambar 7. Lokus P3M STARS YKPN Yogyakarta (2019-2024) Sumber: P3M STARS YKPN Yogyakarta, 2019

Kegiatan PKM dengan kerjasama dengan kelurahan tidak hanya berhenti pada satu tahapan /waktu, tetapi direncankan secara berkelanjutan dari th. 2019-2023.

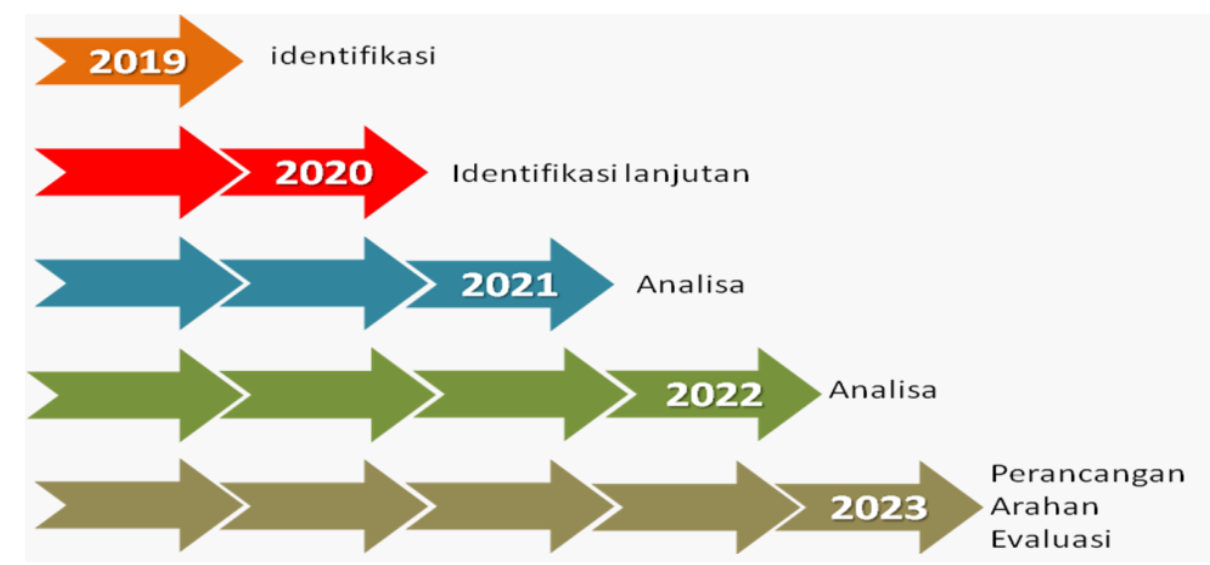

Gambar 8. Tahapan P3M STARS YKPN Yogyakarta (2019-2024) Sumber: P3M STARS YKPN Yogyakarta, 2019

Dalam kurun waktu tahun 2018-2020, kerja sama dengan Kelurahan Notoprajan yang sudah dihasilkan adalah identifikasi dan pemetaan potensi dan permasalahan kawasan, masterplan kawasan, rencana sarpras dan DED kawasan. Dokumen di atas dengan berkolaborasi dengan dokumen perencanaan desa dari program KOTAKU. Rencana tahun 2021 adalah perencanaan Kampung Susun. 


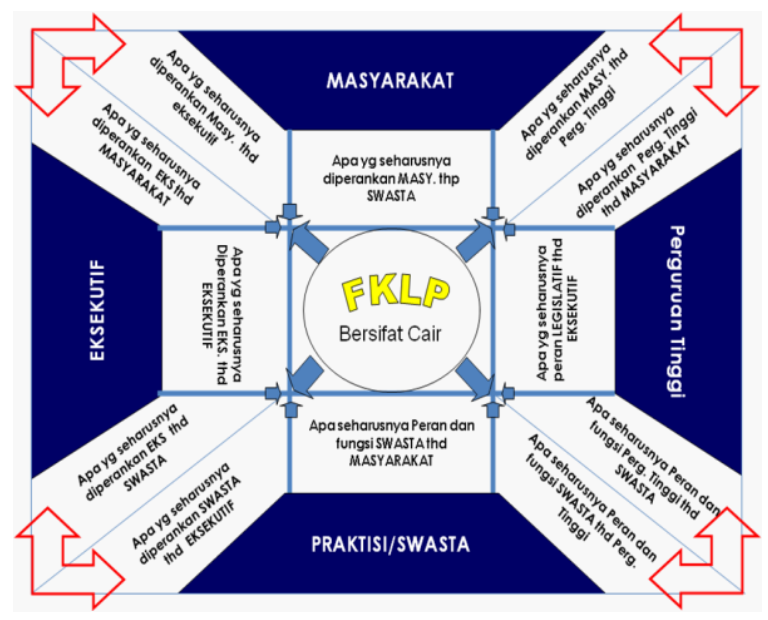

Gambar 9. Pendekatan perencanaan berbasis masyarakat Sumber: Dokumentasi Yunanta, 2020

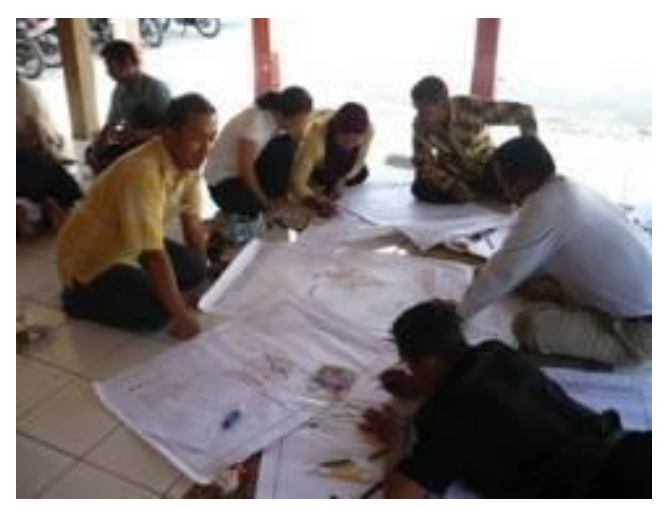

Gambar 10. Rembug perencanaan masyarakat Sumber: Dokumentasi P3M, 2019

\section{Kesimpulan}

Merujuk pada panduan MBKM dan Tridharma Perguruan Tinggi, maka STARS YKPN Yogyakarta telah berusaha mengaplikasikan Keputusan Mendikbud tahun 2020 dengan berbagai kebijakan dan strategi, baik dari sisi kelembagaan institusi, program studi dan kemahasiswaan. Implementasi MBKM adalah setiap bidang kegiatan Tridharma Perguruan Tinggi saling terintegrasi dan saling berkolaborasi, sehingga output dan outcome dapat menjawab tujuan STARS YKPN Yogyakarta.

\section{Bidang Pendidikan dan Pengajaran.}

Kurikulum S1 dimulai pada semester 5, mahasiswa akan keluar program studi untuk melaksanakan magang/kerja praktik, membangun desa (Kuliah Kerja Lapangan) dan studi proyek independen (Studio Perancangan Terpadu), sedangkan kurikulum DIII juga mulai semester 5, untuk melaksanakan magang/kerja praktik dan membangun desa (Kuliah Kerja Lapangan).

\section{Bidang Penelitian}


Penelitian/riset yg dilakukan bersama, dosen sebagai pelaku maupun pembimbing dengan melibatkan mahasiswa. Kegiatan ini bisa merupakan fokus atau lokus KKL dan KP yang terintegrasi dengan riset/penelitian.

\section{Pengabdian Masyarakat.}

Kegiatan pengabdian masyarakat merupakan bagian dari kolaborasi pendidikan, pengajaran dan penelitian.

\section{Daftar Pustaka}

Direktorat Jenderal Pendidikan Tinggi Kementerian Pendidikan dan Kebudayaan. (2020). Buku panduan merdeka belajar kampus merdeka 2020. Jakarta: Direktorat Jenderal Pendidikan Tinggi Kemdikbud RI.

STARS YKPN Yogyakarta. (2020). Rencana strategis STARS YKPN Yogyakarta 2020-2025. Tidak dipublikasikan.

STARS YKPN Yogyakarta. (2020). Rencana induk pengembangan STARS YKPN Yogyakarta 2020-2034. Tidak dipublikasikan.

STARS YKPN Yogyakarta. (2020). Statuta STARS YKPN Yogyakarta. Tidak dipublikasikan. 